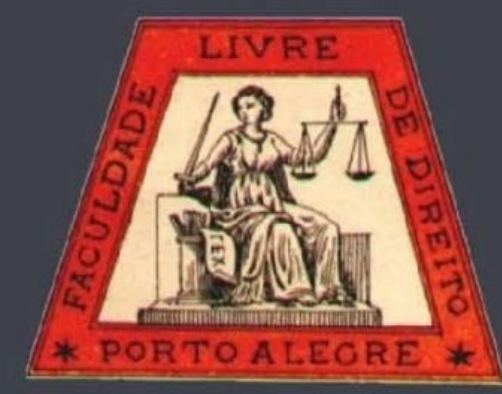

\title{
Guerras ou conflitos pela água: em busca de uma clarificação terminológica
}

Water wars or conflits: in search of a terminological clarification

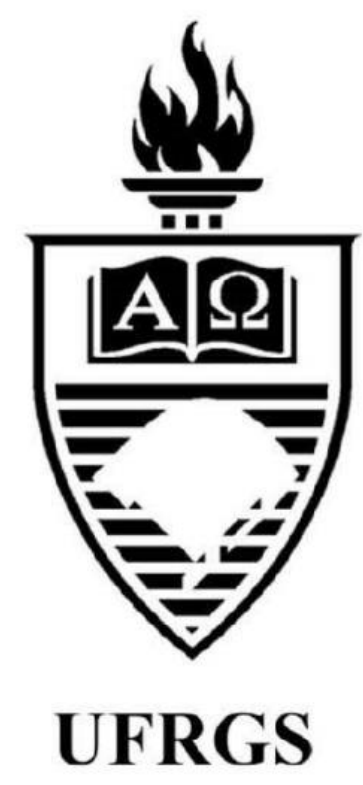

Gildo Manuel Espada

Universidade Eduardo Mondlane, Moçambique

Revista da Faculdade de Direito da UFRGS

ISSN: 0104-6594 Site hitpa//seer,ufrgs.br/revfacdir

Faculdade de Direito da UFRGS - Rua Riachuelo, 1317 - Centro - Porto Alegre - RS - Brasil

CEP- 90010-271 - Telefone: +55 5133083118 - Site http://www.ufrgs.br/direito/ 


\title{
Guerras ou conflitos pela água a nível internacional: em busca de uma clarificação terminológica
}

\author{
Wars or conflicts for water in the international level: in search of a terminological clarification
}

\author{
Gildo Manuel Espada*
}

\section{REFERÊNCIA}

ESPADA, Gildo Manuel. Guerras ou conflitos pela água a nível internacional: em busca de uma clarificação terminológica. Revista da Faculdade de Direito da UFRGS, Porto Alegre, n. 36, p. 164-182, ago. 2017.

\section{RESUMO}

O facto de grande parte dos cursos de água terem uma natureza internacional leva a que os mesmos, naturalmente, sejam vistos como recurso vital por dois ou mais Estados. Acontece, não poucas vezes, que os usos feitos por um Estado, vezes sem conta, põem em causa o direito de uso ou de acesso do recurso por outros Estados. Por este motivo, surge quase sempre a necessidade de cooperação entre os Estados ribeirinhos. Infelizmente, muitas vezes não se chega facilmente a acordo sobre os critérios de tal cooperação, o que despoleta conflitos entre os Estados, que nalguns casos terminam como verdadeiras guerras. A grande questão que se coloca é a de saber se o discurso que é muitas vezes propalado, principalmente pela média, corresponde, de facto, à realidade vivida nas bacias hidrográficas, porquanto fala-se muitas vezes existência de guerras, de conflito ou de tensão causadas pela água quando, na verdade, o que acontece é uma respeitosa troca de missivas. Mas o inverso também é verdadeiro: assistemse a verdadeiros conflitos, e algumas vezes a guerras entre povos e ou nações, causadas pela água, sendo por isso curial esclarecer quais são os critérios usados pelo moderno direito internacional de águas para classificar determinada situação como sendo de conflito, de guerra, de tensão, etc.

\section{PALAVRAS-CHAVE}

Água. Guerras. Conflitos. Estados.

\section{ABSTRACT}

The fact that a great number of water courses have an international nature makes them a vital resource for two or more States. It happens, not a few times, that the uses made by a State, countless times, collides with the right of use or access of the same resource by other States. For this reason, there is almost always a need for cooperation between riparian States. Unfortunately, often states do not reach an agreement on the criteria for such cooperation, and this triggers conflict between States, which in some cases end up as true wars. The big question that arises is whether the discourse that is often used, especially by the media, corresponds, in fact, the reality experienced in the river basins, because we often talk of war, conflict or tension caused by water when, in fact, what happens is a respectful exchange of letters. But the reverse is also true: we witness real conflicts, and sometimes wars between peoples and or nations, caused by water, so it is necessary to clarify what each case as of conflict or war.

\section{KEYWORDS}

Water. Wars. Conflicts. States.

\section{SUMÁRIO}

Introdução. 1. A água como fonte de conflito. 2. Natureza dos conflitos ligados à água. 3. Guerras ou conflitos pela água? Conclusão. Referências.

\section{INTRODUÇÃO}

As águas internacionais, por serem partilhadas por dois ou mais Estados, criam muitas vezes situações políticas complexas que podem gerar disputas e ou conflitos entre os mesmos. Os conflitos relacionados com recursos hídricos podem ter como causa disputas diversas

\footnotetext{
* Doutorando em Direito Público pela Universidade Nova de Lisboa, Portugal. Mestre em Direito Internacional pela Universidade de Macau - UMAC, 2007. Licenciatura em Direito, ramo de Ciências Jurídicas Puras no Instituto Superior de Ciências e Tecnologia de Moçambique - ISCTEM, 2004. Bacharelado em Direito no ISCTEM, 2002.
} 
relativas ao uso e ou acesso aos recursos hídricos; podem ser disputas relacionadas com a demarcação de fronteiras; ou ainda disputas relacionadas com a navegação.

Apesar de os Estados terem o seu traçado fronteiriço claramente identificado, não deve causar estranheza o facto de conflitos de tal natureza acontecerem, na medida em que os recursos transfronteiriços, por definição, atravessam fronteiras, o que faz com que o conceito tradicional de soberania não seja aplicado na sua plenitude.

Governantes e público em geral olham para a água que flui nos seus territórios como sendo um recurso nacional. Legalmente e constitucionalmente, este é um pensamento correcto. Mas o que é visto como sendo " recurso nacional" pode na verdade ser um recurso partilhado. E os recursos hídricos partilhados são quase sempre um bem com alto potencial de competição.

A língua inglesa é bastante eloquente a explicar esta questão: a palavra rival, é originária do latim rivalis, que significa uma pessoa que usa o mesmo rio ou fonte de água, que a outra. Deste modo, percebe-se porque é que os Estados ribeirinhos que partilham a mesma fonte de água são muitas vezes rivais. Considerando a importância da água para o desenvolvimento nacional, cada país terá a sua própria agenda para a exploração dos recursos hídricos internacionais. Pelo que o ponto de partida para qualquer discussão quanto ao fim da cooperação em águas é o reconhecimento de que os Estados soberanos têm, obviamente, agendas próprias, racionais e legítimas, que prevêem a exploração máxima dos benefícios dos recursos hídricos.

A questão que se coloca é: estaremos de facto na iminência de guerras e ou conflitos pela água?

\footnotetext{
1 GIORDANO, Mark F.; GIORDIANO, Meredith A; WOLF, Aaron T. International Resource Conflict and
}

\section{A ÁGUA COMO FONTE DE CONFLITO}

Os recursos hídricos internacionais congregam peculiaridades que os tornam vulneráveis ou ainda focos latentes de ocorrência de conflitos. De entre tais características apontam-se pelo menos três. ${ }^{1}$ Primeiro, há uma tendência de os Estados maximizarem a exploração dos recursos hídricos transfronteiriços, de tal sorte que vezes sem conta o acesso a recursos partilhados por todos os Estados ribeirinhos fica comprometido, em resultado da excessiva exploração feita por outros Estados que partilham o mesmo recurso, regra geral a montante.

Esta situação não é, definitivamente, uma que possa ser considerada como um acto imbuído de dolus malus por parte dos Estados que assim agem, porque as necessidades individuais de cada Estado devem a todo custo ser supridas. Entretanto, é preciso perceber que os benefícios alcançados pelos Estados por via da exploração dos recursos naturais transfronteiriços podem significar custos e sacrifícios para outros Estados que partilham o mesmo recurso, em resultado da redução da quantidade e ou qualidade dos recursos hídricos nos outros países pelos quais eventualmente o mesmo curso é partilhado, principalmente a jusante.

Tal situação faz com que a assimetria existente entre os benefícios do acesso aos recursos hídricos por alguns Estados e os sacrifícios a que se devem outros sujeitar em resultado do uso excessivo ou mau uso de outros Estados, crie a percepção de injustiça na partilha, ou de má fé no uso dos recursos hídricos transfronteiriços.

Em segundo lugar, por receio de que os outros Estados usem excessivamente os recursos hídricos partilhados logo que os mesmos entrem

Mitigation. Journal of Peace Research, v. 42, n. 1, 2005. p. 56. 
no seu território, os Estados criam um sentido de egoísmo derivado da mentalidade segundo a qual "se não faço eu a exploração do recurso o outro a fará", pelo que os Estados acabam explorando mais do que na verdade necessitam ou ainda de forma menos racional do que o fariam numa situação em que não tenham concorrência. Esta situação leva geralmente a uma má exploração dos recursos partilhados, que podem criar um clima de tensão e até de conflito entre os Estados.

Em terceiro lugar, os recursos hídricos partilhados, pela sua natureza, carecem de esforço conjunto de todas as partes que os usam, o que obriga a que haja um esforço conjunto que deve muitas vezes redundar em acordos entre as partes envolvidas. Mas este não é, definitivamente, um processo fácil, quer pela natureza do recurso, dos interesses individuais dos Estados, ou ainda das boas ou más relações que previamente tenham existido entre os Estado.

Daí que a celebração de acordos, o grau de implementação dos mesmos e ainda o grau de conformação dos Estados a tais tratados é um verdadeiro desafio para os Estados, mas que pode suscitar conflitos resultantes de quezílias já existentes entre os mesmos. Pelo que a acção colectiva que se possa querer alcançar na gestão dos recursos hídricos transfronteiriços, por via de acordos, põe em causa interesses particulares dos Estados, com limitação de soberania, e coloca desafios jurídicos que, não sendo bem conduzidos, podem provocar o distanciamento entre os Estados. ${ }^{2}$

Surge deste modo o termo " independência hidrológica”, que é relacionado aos Estados que partilham recursos hídricos, e lhes é reconhecido o direito soberano de explorar esses mesmos recursos. E há três áreas de preocupações, ou de interesse, se quisermos, que podem ser levantadas entre os países que partilham águas: os interesses relacionados com a soberania; os interesses relacionados com a integridade territorial; e os interesses relacionados com a segurança nacional.

Um curso de água internacional interliga os vários Estados ribeirinhos num sistema complexo de interdependência, que cobre diversas esferas como a económica, a das políticas ambientais e a segurança. A dinâmica de tais relações entre os Estados ribeirinhos torna-se muito frágil quando se assiste a uma crescente escassez de água, quando os valores acima referidos atingem o seu limite.

Tal facto pode levar à perda de independência hidrológica, passando os Estados a ser interdependentes. E a interdependência hidrológica em bacias hidrográficas com escassez de água pode criar não só um potencial para conflitos entre os Estados de bacia, como também pode ser um excelente potencial para a cooperação entre esses mesmos Estados.

Daí que as águas internacionais careçam de uma gestão cuidadosa a nível nacional, no respeito pelos regimes de gestão comum que deve ser feito a nível da bacia hidrográfica como um todo, de forma coerente, por todos os Estados de bacia. Por essa razão, não há dúvidas que uma governação de águas efectiva é a melhor solução para enfrentar os desafios colocados nas bacias hidrográficas internacionais. Como é que, a nível jurídico, esta gestão pode ser promovida e deve ser feita, é uma das questões que bem respondida, permite reduzir os níveis de conflitualidade.

Se por um lado alguns recursos hídricos internacionais são geridos por via de cooperação entre os diversos Estados de bacia, há sempre questões que se levantam em relação a esta mesma gestão. De um ponto de vista de equidade, a existência de assimetrias de poder entre os Estados ribeirinhos (em termos de poder económico, capacidade militar, tamanho do

\footnotetext{
${ }^{2}$ BENVENISTI, Eyal. Collective Action in the Utilization of Shared Freshwater: The Challenges of International Water Resources Law. AJIL, v. 90, n. 3, 1996. p. 385.
} 
Estado, etc.) pode interferir na obtenção de um acordo justo e sustentável entre os Estados que partilham águas, e é uma potencial causa de conflitos.

Conseguir um acordo aceitável, e acima de tudo justo, é por isso de grande importância, uma vez que para além de mitigar o risco de conflito, tal facto pode afectar positivamente o processo da partilha equitativa entre os países ribeirinhos. Pelo que as políticas em relação às quais determinada bacia hidrográfica se subordina providencia os parâmetros dentro dos quais a gestão dos recursos hídricos transfronteiriços deve ser analisada. Daí a razão pela qual é impossível desligar as questões relativas a recursos hídricos dos demais cenários políticos existentes.

Pelo contrário, é preciso fazer uso do potencial poder unificador que um curso de água internacional providencia para melhorar a partilha de benefícios, aprofundar o diálogo e dessa forma melhorar o desenvolvimento económico. ${ }^{3}$

A celebração de acordos de bacia tem sido, por isso, a solução prática para evitar e ou resolver conflitos sobre águas transfronteiriças. Devido à cada vez maior degradação da qualidade da água e à redução da quantidade disponível em face dos cada vez maiores usos existentes, e com a natural intensificação da competição pelo acesso à água pelos diferentes usuários, a celebração de acordos apresenta-se muitas vezes como a solução mais prática das várias possíveis.

A questão que se coloca muitas vezes nem é, até, a possibilidade de ocorrência de conflitos, pois, em muitos casos, mais do que causar possíveis conflitos, a necessidade de partilha de água promove situações de cooperação quando menos se espera.

${ }^{3}$ TURTON, Anthony R. Hydro hegemony in the context of the Orange River basin. Paper presented at the Workshop on Hydro Hegemony, Kings College and the School of Oriental and African Studies (SOAS), Londres, 20-21 mai. 2005.
Nos últimos 50 anos, foram celebrados mais de 150 tratados sobre águas, ${ }^{4}$ e tais números mostram a importância da diplomacia na questão das águas, que torna as relações entre os Estados, no que à água diz respeito, mais estáveis e previsíveis. A história dos tratados sobre águas datam de a 2500 a.C. quando as cidades sumérias de Lagash e Umma celebraram um acordo que fez cessar uma disputa sobre o rio Tigris, sendo o referido tratado reputado como tendo sido o primeiro tratado do género na solução de disputas sobre águas. ${ }^{5}$

Desde então, um grande número de tratados sobre águas tem sido celebrado. De acordo com a FAO, mais de 3600 tratados sobre cursos de águas internacionais foram celebrados desde 805 A.C. sendo a grande maioria de tais tratados relacionase com questões navegacionais e traçados de fronteira. ${ }^{6}$

Entretanto, desde o século passado que se tem assistido a uma mudança de enfoque no objecto dos tratados, que passaram de questões navegacionais para as relativas ao uso, exploração, protecção e conservação dos recursos hídricos. Os mais de 3600 acordos e tratados são de facto um grande ganho, se olharmos para os números. Todavia, há ainda muitas fraquezas que devem ser ultrapassadas.

$\mathrm{O}$ monitoramento dos acordos e mecanismos práticos que garantam o cumprimento dos acordos, e normas específicas que permitam a alocação de quotas de água tendo em conta a alteração dos caudais e a situação específica dos Estados ribeirinhos (quer sejam de montante ou de jusante) e ainda a mudança nas

${ }^{4}$ UNITED NATIONS. Transboundary Waters. Water for life decade. Disponível em: <http://www.un.org/waterforlifedecade/transboundary_wat ers.shtml>. Acesso em: 15 mai. 2017.

${ }^{5}$ Ibid.

${ }^{6}$ Ibid. 
necessidades de cada Estado são alguns dos pontos que precisam de ser melhorados. ${ }^{7}$

Há de facto consenso entre os peritos em águas em como os acordos sobre cursos de água devem ser mais concretos, com previsão de normas que estabelecem o cumprimento dos tratados celebrados e que incorporem normas sobre a resolução de conflitos de forma detalhada, caso os mesmos ocorram, pois uma melhor elaboração de normas pode prevenir também os conflitos.

Para tal, um conhecimento mais claro da situação da bacia hidrográfica permite a elaboração de normas mais eficazes e concretas, com alusão aos mecanismos de alocação de água mais eficazes, o estabelecimento de níveis de qualidade de água que devem ser mantidos e respeitados, que sejam práticos mas também flexíveis, que considerem eventos hidrológicos, mudanças na dinâmica da bacia hidrográfica e os diversos valores sociais existentes. ${ }^{8}$

Quando se discute a questão da segurança ambiental $^{9}$, é comum referir-se o potencial de conflito na área dos recursos hídricos transfronteiriços como alto, e factos recentes em vários quadrantes do mundo assim o provam, sendo vasta a literatura sobre conflito e cooperação que tenha como objecto cursos de água internacionais. Das várias posições sobre o assunto, há quem defenda a existência de um nexo

\footnotetext{
${ }^{7}$ Ibid.

${ }^{8}$ Ibid.

${ }^{9} \mathrm{O}$ conceito de segurança ambiental é despoletado, de entre outros factores, pelo debate em torno dos conflitos causados pela disputa de recursos naturais. Tal conceito é entendido como a necessidade de protecção dos recursos naturais nacionais. Para além deste entendimento, o conceito de segurança ambiental inclui outras situações, como as mudanças climáticas e questões sobre integridade territorial e ainda a estabilidade política que estejam relacionadas com a exploração de recursos naturais. Vide HOMER-DIXON, Thomas F. On the threshold: Environmental changes and acute conflict. International Security, v. 16, n. 2, 1993. p. 98.

${ }^{10}$ AMERY, Hussein A. Water, War and Peace in the Middle East: Comments on Peter Beaumont. The Arab World Geographer, v. 4, n. 1, 2008. p. 51.
}

de causalidade entre a água e a guerra, em certos contextos, existindo várias evidências e literatura sobre conflitos violentos causados pela partilha da água. ${ }^{10}$

Do ponto de vista teórico, a explicação geralmente dada para os conflitos causados pela partilha de recursos hídricos internacionais é a de tais recursos constituírem um caso especial e complexo de "common pool resources". ${ }^{11}$ Esta 'common pool' é, entretanto, comprometida pelo facto de os Estados serem soberanos por natureza e operarem num sistema internacional que é anárquico porque não se consegue impor à leviandade dos sujeitos do Direito Internacional e que opera em grande medida sem nenhuma autoridade central internacional, o que faz com que os Estados se preocupem por zelar pelos seus interesses nacionais, em detrimento dos interesses internacionais. $^{12}$

Analisando a literatura jurídica que defende a ideia de existência de uma interligação entre a escassez de água e o surgimento de conflitos, nota-se que os conflitos verificados surgiram ou agudizaram-se nos últimos 20 anos, sublinhando alguns autores o perigo de violência que pode surgir a qualquer momento à volta das águas internacionais. ${ }^{13}$

Em Março de 2001, o então Secretário-geral das Nações Unidas, Kofi Anan, expressou o receio da proliferação dos conflitos que tenham

${ }^{11}$ International pool resources é uma expressão usada para indicar os recursos partilhados por dois ou mais Estados, sendo exemplo os cursos de água transfronteiriços, em que o uso num certo país pode criar impactos noutros ou noutros.

12 PHILIPS, David J. H.; DAOUDY, Marwa; MACCAFFREY, S.; ÖJENDAL, Joakim; TURTON, Anthony. Trans-boundary Water Cooperation as a Tool for Conflict Prevention and for Broader Benefit-sharing. Ministry for Foreign Affairs, Stockholm, Sweden, 2006. p. 27.

13 GLEICK, Peter H. Water and Conflict: Fresh Water Resources and International Security. International Security, v. 18, n. 1, 2003. p. 94. 
como causa a água dizendo que “... if we are not careful, future wars are going to be about water and not about oil..."14, e com isto expressando o receio de tais conflitos tornaram-se ideologicamente hegemónicos. O mesmo receio já foi igualmente expresso por Ban Ki-Moon. ${ }^{15}$

Pelo peso de tais afirmações, e de forma a não subestimar ameaças reais à estabilidade futura, parece claro que o receio não deve ser visto como meras hipóteses académicas, mas um assunto que deve ser discutido ao mais alto nível político. Na verdade, a competição pela água é tão real que seria uma infantilidade não levar $o$ assunto a sério, pois este é um facto inquestionável. ${ }^{16}$

Entretanto, porque nalgum momento dúvidas pairaram em relação ao real perigo que os potenciais conflitos sobre a água tem criado, e porque na prática não se encontrava uma ligação causal entre a escassez de água e o surgimento de conflitos, várias questões foram levantadas, no médio oriente, considerado por muitos o principal foco de conflitos latentes sobre a água. Dentre elas, questões como 'qual é a quantidade de água renovável existente dentro dos limites de cada Estado? Qual é o grau de escassez existente?', foram levantadas.

Para responder a esta pergunta, e de forma a não generalizar, fez-se um estudo de caso no Médio Oriente, em que várias análises de diferentes âmbitos foram feitas por engenheiros e hidrologistas, determinando as precisas quantidades de água disponível em cada um dos Estados daquela região, e os resultados foram

\footnotetext{
14 ANNAN, Kofi. Question and answer session after statement at the Federation of Indian Chambers of Commerce and Industry. SG/SM/7742, New Delhi, 15 mar. 2001.

15 ZEITUN, Mark; MIRUMACHI, Naho. Transboundary water interaction I: reconsidering conflict and cooperation. International Environmental Agreements, Springer, 2008. p. 2.

${ }^{16}$ TROTTIER, Julie. Water Wars: The Rise of a Hegemonic Concept. Exploring the making of the water war and water peace belief within the Israeli-Palestinian Conflict. Water
}

considerados de bastante preocupantes. ${ }^{17} \mathrm{Os}$ resultados mostraram, por exemplo, que países como a Turquia, o Líbano e o Iraque eram considerados como possuidores de reservas de água adequadas, enquanto Israel, Jordânia e a Faixa de Gaza estavam muito aquém do mínimo necessário. Tal desigualdade foi considerada extremamente perigosa, pois podia levar a que os países com escassez de água fizessem guerras contra os Estados ricos em água.

Por isso, e desde então, este assunto passou a ser o tópico de estudos detalhados sobre relações internacionais, e o cerne da questão, a nível jurídico, passou a ser como é que o Direito Internacional de Águas pode contribuir para uma partilha sustentável das águas entre os Estados, tendo sido sugeridos vários critérios de redistribuição das águas entre os diversos países que partilham bacias hidrográficas. ${ }^{18}$

Entretanto, considerando que os estudos iniciais sobre o surgimento de conflitos e ou disputas pela água foram feitos no Médio Oriente ${ }^{19} \mathrm{e}$ tendo em conta que uma boa parte dos conflitos passados e latentes sobre a água estão ligados àquela região do mundo, pode-se questionar se não estaríamos a generalizar um problema que é local. Mas, não nos parece que esse seja o caso. Várias outras regiões do mundo, incluindo a África Austral, tal como veremos, são regiões propensas à ocorrência de conflitos, que podem ser mais ou menos intensos dependendo da forma como a questão é encarada e da capacidade dos actores em encontrar soluções práticas.

for Peace: A Cultural Strategy. UNESCO-IHP, 2003. p. 137.

${ }^{17}$ ELMUSA, Sharif S. Dividing the Common PalestinianIsraeli Waters: An International Water Law Approach. Journal of Palestine Studies, v. 22, n. 3, 1993. p. 69.

18 BENVENISTI, Eyal; GVIRTZMAN, H. Harnessing International Law to Determine Israeli- Palestinian Water Rights: The Mountain Aquifers. Natural Resources Journal, v. 33, n. 3, 1993. p. 558.

${ }^{19}$ TROTTIER, op. cit., p. 146. 
De acordo com Peter Gleick, os conflitos pela água podem resultar de uma das seguintes razões ${ }^{20}$ :

- Água como um objectivo político e ou militar: aqui apontam-se os casos da bacia do rio Jordão (envolvendo a Síria, o Israel, e a Jordânia); a bacia do rio Colorado (entre o México e os Estados Unidos); e a bacia do rio Danúbio, (envolvendo a Eslováquia e a Hungria).

- Água como instrumento ou ferramenta de conflito: e aqui apontam-se o Rio Han, (envolvendo a Coreia do Norte e a Coreia do Sul); o rio Eufrates (envolvendo a Turquia, a Síria e o Iraque); e o complexo esquema de importação e redistribuição de água estabelecido entre a Malásia e a Singapura.

- A água e os sistemas de água como alvos de um conflito: aqui aponta-se o caso de destruição pelo Iraque dos silos de dessalinização da água salgada existentes no Kuwait.

As desigualdades no uso, distribuição e exploração da água são, talvez, a forma mais visível dos conflitos mundiais sobre a água, e que afecta muitos rios pelo mundo fora, de entre os quais se indicam o Mekong, o Ganges, o Jordão, o Tigris, o Orontes, o Colorado, o Indus, o Brahmaputra, o Rio Grande, o Amazonas, o Paraná, o Congo, o Zambeze, o Níger, o Senegal, o Orange, o Okavango, o Nilo, o Limpopo, o Incomáti, etc.

Há quem refira como alarmistas os vários discursos das figuras políticas que referem as guerras sobre a água como iminentes, desacreditando-os. Entretanto, é uma realidade o facto de muitos Estados consideram a água de extrema importância para o seu desenvolvimento e ou sobrevivência, o que leva a que de forma geral haja uma preocupação em garantir a alocação necessária para satisfazer as necessidades individuais dos Estados, o que torna a questão da água (acesso, uso e gestão) como uma questão de segurança prioritária, em antecipação de conflitos. E definitivamente, ameaças e discursos belicistas entre os Estados, causados pela água, é o que não falta.

Mas, procurando fazer uma análise actualista da possibilidade de ocorrência de conflitos, tendo em conta a evolução global da problemática da água, refira-se que já na década de 1990 as previsões de escassez de água eram suficientes alarmantes, principalmente em regiões semi-áridas, de tal sorte que muita "agitação" fezse sentir na tentativa de garantir o acesso aos recursos, uma vez que os Governos estavam desejosos de garantir a segurança no acesso e abastecimento de água a todo o custo, mesmo nas circunstâncias mais hostis. Nalgumas situações referiram-se a existência de crises, noutras de tensões, noutras ainda, de guerra. Não tardou por isso a que regiões como o Médio Oriente, no rio Indu e as bacias dos rios Ganges e Bramaputra fossem vistas como potencialmente voláteis a conflitos pela água, pela crescente tensão.

Foram estas as razões pelas quais muitos previram verdadeiras hecatombes, em face de eminentes conflitos armadas, pois algumas situações alimentaram as especulações. Por exemplo, o Egipto ameaçou entrar em Guerra com os países de montante que partilham o rio Nilo, se os mesmos continuassem a fazer a exploração da água para além do que prevê um acordo colonial ainda em vigor.

Outras razões do surgimento de conflitos pela água prendem-se com o aumento do número de países que partilham as bacias hidrográficas internacionais, em consequência do surgimento de novos Estados, o que faz com que o número de bacias hidrográficas internacionais também aumente. $\mathrm{O}$ aumento da internacionalização das bacias hidrográficas mundiais espelha-se no

${ }^{20}$ GLEICK, Peter H. The World's Water: The Biennial Report on Freshwater Resources 1998-1999. Washington, D.C.: Island Press. p. 42. 
aumento de bacias hidrográficas internacionais que passou de 214 em 1979 para 263 em 2002, situação que deveu-se ao desmembramento de alguns Estados ou federações como a União das Repúblicas Socialistas Soviéticas. ${ }^{21}$

Outra causa de conflito pela água tem a ver com a existência e ou disponibilidade dos recursos hídricos existentes nas bacias hidrográficas internacionais, dependendo de eventos como cheias ou secas, que podem ser o factor que despoleta conflitos. Assim, caso não haja instituições fortes a nível das bacias hidrográficas, a possibilidade de ocorrência de conflitos é grande, pois os desafios que se colocam ultrapassam muitas vezes a capacidade de gestão de crise existente, pelo que apesar da importância da existência das instituições de gestão de bacias hidrográficas, a sua mera presença é insuficiente para prevenir a ocorrência de conflitos. ${ }^{22}$ Daí que a previsão de conflitos pela água e os esforços para mitigá-los, não devem limitar-se à criação de instituições de bacia, mas também na garantia efectiva de as mesmas estarem capacitadas para enfrentar os muitos desafios que se colocam, incluindo mudanças a nível de existência e disponibilidade de recursos, mudanças sociopolíticas, etc.

Estas são as razões pelas quais não duvidamos da existência de verdadeiros conflitos

\footnotetext{
${ }^{21}$ E este número irá certamente subir, considerando que a fonte aqui citada não incluíu por exemplo os dados das bacias hidrográficas internacionais surgidas nos últimos 10 anos. Vide GIORDANO, Mark F.; GIORDIANO, Meredith A; WOLF, Aaron T. International Resource Conflict and Mitigation. Journal of Peace Research, v. 42, n. 1, 2005. p. 57.

${ }^{22}$ Para elucidar tais situações, é apontado o caso da partilha das águas do rio Colorado, entre os Estados Unidos e o México, por via de um Tratado de 1944. Infelizmente, o cálculo do fluxo de água que determinou a alocação de recursos para cada uma das partes foi feito numa época alta, chuvosa, e quando os níveis de descarga reduziram mais tarde, em consequência da falta de precipitação, surgiu de imediato uma disputa entre as partes. Vide GIORDANO, Mark F.; GIORDIANO, Meredith A; WOLF, Aaron T. International Resource Conflict and Mitigation. Journal of Peace Research, v. 42, n. 1, 2005. p. 57.
}

pela água, que nos levam a perceber o porquê de nalgum momento se ter falado, nos meados de 1990 da ideia de uma "Guerra pela água”, que na altura tornou-se popular, tanto nos meios académicos assim como político, o que levou a um discurso de 'secutirização', tornando-se a água uma questão de segurança nacional.

Algumas vezes, a crise à volta dos recursos hídricos internacionais cria situações tensas, não conflituosas, mas de prontidão por parte dos Estados, para possíveis eventualidades, a que se chama 'secutirização'. O processo de 'secutirização' ocorre quando a situação está num estado crítico em relação às necessidades de um Estado, no sentido de a alocação da água e os usos da mesma tornar-se uma questão de preocupação nacional requerendo por isso atenção ${ }^{23}$, e muitas das bacias hidrográficas internacionais da região da África Austral são exemplo. ${ }^{24} 25$

As instituições conjuntas de gestão de bacias hidrográficas são um exemplo de bacias hidrográficas 'dessecurizadas' e algumas vezes têm um papel mais importante que os acordos regionais existentes, no exemplo do Protocolo de Águas da SADC (Southern África Development Community), sendo por isso reconhecida muita importância às instituições e acordos regionais

23 TURTON, Anthony R. The Political Aspects of Institutional Development in the Water Sector: South Africa and its International River Basins. 2003. Tese (Doutorado em Ciência Política)-University of Pretoria, Department of Political Science, 2003. p. 198.

24 TURTON, Anthony R. The hydropolitical dynamics of cooperation in Southern Africa: A strategic perspective on institutional development in international river basins. In: TURTON, A.; ASHTON, P.; ClOETE, T. E. (Ed.). Transboundary Rivers, Sovereignty and Development: Hydropolitical Drivers in the Okavango River Basin. Pretoria e Genebra: African Water Issues Research Unit e Green Cross International, 2003. p. 91.

${ }^{25}$ LIBISZEESKI, Stephan. Water Disputes in the Jordan Basin Region and their Role in the Resolution of the ArabIsraeli Conflict. Occasional Paper No. 13. Center for Security Studies and Conflict Research, Zurique, 1995. p. 30 . 
por criarem uma plataforma de gestão coerente dos recursos hídricos. ${ }^{26} 27$

Deste modo, e sumarizando, podemos ter situações em que a água tem diferentes papéis num conflito, podendo a água ser "objecto" do conflito, quando os Estados disputam o acesso à mesma ou a poluição nela causada; A água pode ser também "instrumento" de um conflito, nas situações em que por exemplo um Estado de montante polui propositadamente a água, ou então procede a transferências de água ou limita o fluxo da mesma de modo a pressionar o Estado de jusante, limitando o acesso deste à água, só para pressioná-lo; e a água pode também ser um verdadeiro catalisador de conflitos internacionais, causados pela escassez de água que pode causar uma crise internacional. ${ }^{28}$

\section{NATUREZA DOS CONFLITOS LIGADOS À ÁGUA}

Uma coisa é o papel da água como factor de conflitos. Outra é a existência de um conflito real ou latente. Outra coisa ainda é a existência de uma guerra, real ou declarada, pela água. Em suma, a determinação natureza e o grau de intensidade dos conflitos ligados à água é um assunto actual da geopolítica mundial, que determina a maior ou menor preocupação em relação ao assunto, e que desde já passa a merecer a nossa atenção.

\footnotetext{
26 HEYNS, Piet S. SADC agreements in existence pertaining to shared water resources. In: Water and Security in Southern Africa, SIDA, Stockholm, 1995. p. 59.

27 TURTON, Anthony R. The evolution of water management institutions in selected Southern African international river basins. In: TORJADA, C.; UNVER, O.; BISWAS, A. K. (Ed.). Water as a Focus for Regional Development. Londres: Oxford University Press, 2004. p. 263.

28 MOSTERT, Erik. Conflict and Cooperation in the Management of International Freshwater Resources: A Global Review. UNESCO-IHP, n. 19, 2003. p. 16.

${ }^{29}$ GIORDIANO, Mark A.; WOLF, Aaron T. Sharing waters: Post-Rio international water management. Natural Resources Forum, 27, 2003. p. 169.
}

Uma das dificuldades enfrentadas no debate sobre os conflitos ligados à água tem a ver com o facto de os referidos conflitos variarem de intensidade, havendo quem refira inclusive que de acordo com o grau de intensidade podemos estar numa situação de "conflito quente" ou "conflito frio", que antecedem ao surgimento de verdadeiros conflitos armados, e o mesmo espectro de relações pode existir em relação à cooperação existente entre os Estados em litígio. ${ }^{29}$

E salta ainda à vista o facto de os defensores da tese segundo a qual a água é uma fonte de conflitos preocuparem-se mais com a natureza do conflito e não com as raízes que o originam. Por outras palavras, os conflitos sobre águas são geralmente estudados e analisados sem que se indique as suas causas, quer sejam étnicas ou económicas, ambientais, ou ainda uma combinação das várias causas. ${ }^{30}$

Outros autores fazem a discussão doutra forma, referindo a existência de um problema fundamental, que é derivado do facto de no que aos conflitos sobre a água diz respeito, não se cuidar de distinguir entre conflitos baseados em direitos existentes e conflitos causados por pretensões (legítimas ou não) ${ }^{31}$, e o uso de uma escala expansiva de conflito e cooperação ajuda a ter uma visão mais aprofundada das relações inter-Estatais e os motivos de tais relações, sendo certo que um desses motivos são os recursos hídricos partilhados. ${ }^{32}$

${ }^{30}$ REUSS, Martin. Historical Explanation and Water Issues. Water for Peace: A Cultural Strategy. UNESCO-IHP, 2003. p. 43.

31 Vide MOHAMED-KATERERE, Jennifer; VAN DER ZAAG, Pieter. Untying The 'Knot of Silence'. Making Water Policy and Law Responsive to Local Normative Systems. Water for Peace: A Cultural Strategy. UNESCOIHP, 2003. p. 179.

${ }^{32}$ UNITED NATION DEVELOPMENT PROGRAMME. Human Development Report Office Occasional Paper: Managing Trans-boundary Waters for Human Development, 2006. p. 9. 
Uma segunda linha de pensamento emergiu nos anos 1990, recusando a causalidade entre a escassez de água e os conflitos internacionais desenvolveu o conceito de "água virtual" para descrever a água necessária para produzir alimentos importados. ${ }^{33} \mathrm{~A}$ importação de uma tonelada de alimentos é considerada virtualmente equivalente à importação da quantidade de água necessária para produzir esses mesmos alimentos. J.A. Allan demonstrou que "circulava" no médio oriente mais água virtual do que a quantidade total de água que "circulava" no Nilo.

Por isso, a segurança alimentar não implica necessariamente auto-suficiência alimentar. Colocadas as coisas nestes termos, calculando os índices de stress hídrico com base na capacidade de produção agrícola, não é possível prever a possibilidade de ocorrência de guerras ou conflitos entre Estados. Daí que o autor que referimos defenda que os Estados dos países de regiões áridas e semi-áridas tem mais a ganhar esforçando-se por uma cooperação com vista a manter o preço dos cereais baixos no Mercado internacional do que em guerras com vista a apropriarem-se da água para a produção agrícola.

Entretanto, isto não significa que os Estados devam abdicar dos seus recursos, nem tão pouco que todos os Estados têm capacidade financeira para comprar os alimentos necessários para as suas populações. Muito pelo contrário, e exemplificando com base nos países da região da SADC, onde quase todos tem perfeitas condições para a prática da agricultura, os países vêem-se vezes sem conta na iminência de conflitos porque a água tem que chegar às populações, porque a agricultura e a criação de gado são as principais actividades de subsistência.

\footnotetext{
33 J ALLAN, J. A. Nile Basin Water Management Strategies. In: HOWELL, P. P.; ALLAN, J. J. (Ed.). The Nile: Sharing a Scarce Natural Resource: A Historical and Technical Review of Water Management and of Economic and Legal Issues, 1996. p. 313.
}

No que pode ser considerado provavelmente o mais ambicioso estudo sobre águas internacionais e tratados sobre águas existentes até aqui produzido, Aaron Wolf argumenta que a água trouxe mais cooperação entre Estados do que conflitos. ${ }^{34}$ Ele analisou 412 crises entre estados ribeirinhos, crises essas ocorridas entre 1918 e 1994, e identificou somente sete casos nos quais as questões ligadas à água contribuíram directamente para a disputa, provando os dados empíricos da afirmação atrás feita.

De forma geral, os parâmetros identificados como sendo indicadores de conflitos sobre águas são muitas vezes tenuemente relacionados com as disputas existentes, mas a capacidade institucional existente na bacia hidrográfica, seja em forma de órgãos institucionais ou acordos existentes ou ainda relações internacionais positivas entre as partes, são tão ou ainda mais importantes do que os aspectos físicos de um sistema. $^{35}$

Por isso, apontam-se as mudanças bruscas, sejam institucionais ou físicas do complexo sistema de recursos hídricos internacionais como sendo a causa de muitos conflitos, tal como se reflecte nos dois seguintes conjuntos de indicadores: Bacias hidrográficas "Internacionalizadas", isto é, bacias hidrográficas que incluem as estruturas de gestão de Estados recentemente independentes.

Bacias hidrográficas que incluem projectos de exploração unilaterais sem a existência de regimes de cooperação.

\section{GUERRAS OU CONFLITOS PELA ÁGUA?}

34 WOLF, Aaron T. Conflict and Cooperation Along International Waterways. Water Policy, v. 1, n. 2, 1998. p. 258.

${ }^{35}$ WOLF, Aaron T.; YOFFE, Shira B.; GIORDANO, Mark. International Waters: Indicators For Identifying Basins At Risk. UNESCO-IHP, n. ${ }^{\circ} 20,2003$. p. 7. 
Os recursos de água - a sua escassez, distribuição e qualidade - já foram referidos como factor que pode causar pressão e instabilidade política. Tal instabilidade, geradora de conflitos de maior ou menor intensidade, são vistos muitas vezes como prenúncio de guerras pela água. E, apesar de guerras pela água não terem acontecido na era moderna, há uma evidência ampla de que a falta de água já provocou muita instabilidade, com ocorrência de violência aguda em resultado dessa mesma instabilidade. E o motivo de erupção de conflitos é em grande medida relacionada com a quantidade e a qualidade dos recursos hídricos existentes: quanto mais limitada e ou degradada a quantidade e ou qualidade da água, mais instável será a estabilidade de determinada região. ${ }^{36}$

Como referido, grande parte da literatura que se refere à Guerra sobre a água usa como objecto de Estudo o Médio Oriente, especialmente o conflito Israelo-Árabe. Os autores que promovem esta linha de pensamento argumentam que os Estados que enfrentam a escassez de água e cooperam de forma a ultrapassar tais problemas fazem-no simplesmente porque é a coisa mais racional a fazer. Daí o surgimento de um "discurso de cooperação", que incide no potencial para atitudes de colaboração sobre questões ligadas à água, e a possibilidade de iniciar relações amistosas, e não conflituosas.

É esta a interpretação do conceito de cooperação em águas, em voga até aos dias de hoje. Não existe, todavia, uma única interpretação do conceito de "cooperação", como defendem

\footnotetext{
${ }^{36}$ Ibid, p. 8.

37 PHILIPS, David J. H.; DAOUDY, Marwa; MACCAFFREY, S.; ÖJENDAL, Joakim; TURTON, Anthony. Trans-boundary Water Cooperation as a Tool for Conflict Prevention and for Broader Benefit-sharing. Ministry for Foreign Affairs, Stockholm, Suécia, 2006. p. 26.

${ }^{38}$ WOLF, Aaron T.; YOFFE, Shira B.; GIORDANO, Mark. International Waters: Indicators For Identifying Basins At Risk. UNESCO-IHP, n. ${ }^{\circ} 20,2003$. p. 8.

39 UNITED NATION DEVELOPMENT PROGRAMME. Human Development Report Office Occasional Paper:
}

alguns autores, com quem perfilhamos. ${ }^{37}$ Por isso mesmo, o nível de cooperação internacional a nível do sector de águas ultrapassa, de longe, o nível de conflitos existente. ${ }^{38}$

De facto, as últimas guerras pela água assistiram-se no período da antiguidade, não tendo existido guerras pela água há mais de 4.000 anos, tendo as últimas ocorrido na região que é hoje conhecida como Iraque. Aliás, apesar do legado histórico belicista pela água, aquele país tende hoje a resolver os conflitos relacionados com águas internacionais por via da cooperação e não de guerras. Este ponto de vista mais optimista vê a competição pela água como um catalisador de maior cooperação no futuro ${ }^{39}$, tanto mais que as evidências históricas assim o comprovam. ${ }^{40}$

Mais importante ainda, é necessário ter em consideração que a água está ligada a muitas situações de violência a nível interno dos Estados, variando desde conflitos étnicos, religiosos e tribais, conflitos entre sectores e até entre províncias, pelo uso da água, e que ninguém quer ver tais conflitos repetidos e muito menos intensificados. ${ }^{41}$

Deste modo, o sentimento nacional de repulsa em relação aos conflitos relacionados com a água, e as experiências passadas, havendo, de cooperação de forma a ultrapassar as disputas pela água também devem ser vistos como elemento dissuasor da ocorrência de guerras e elemento propulsor da cooperação internacional.

O corolário feliz da água como elemento mitigador de conflitos e consequentemente de guerras é o facto de a água, pela sua natureza, ser

Managing Trans-boundary Waters for Human Development, 2006. p. 203.

${ }^{40}$ LIBISZEESKI, Stephan. Water Disputes in the Jordan Basin Region and their Role in the Resolution of the ArabIsraeli Conflict. Occasional Paper No. 13. Center for Security Studies and Conflict Research, Zurique, 1995. p. 186. Vide igualmente WOLF, Aaron T. Conflict and Cooperation Along International Waterways. Water Policy, v. 1, n. 2,1998 . p. 257.

${ }^{41}$ WOLF, Aaron T. Conflict And Cooperation. Survey of the Past and Reflection for the Future. Water for Peace: A Cultural Strategy. UNESCO-IHP, 2003. p. 93. 
um elemento que induz à cooperação mesmo aos Estados ribeirinhos hostis, incluindo mesmo as disputas tenham objecto diferente da água. ${ }^{42}$ Este factor, e os outros acima referidos é que fazem com que as disputas causadas pela escassez de água não sejam muitas, e as poucas existentes não se transformem em verdadeiras guerras, apesar de reconhecermos que a escassez de água em quantidade e qualidade é um dos maiores factores de desestabilização nas regiões que partilham bacias hidrográficas.

A água é, na verdade, mais um factor de aproximação das sociedades do que de conflito. De facto, entre os anos 805 e 1984 foram celebrados mais de 3600 tratados relacionados com a água ${ }^{43}$, e de 1948 para cá somente 37 incidentes ou conflitos agudos relacionados com a água foram registados e no mesmo período de 1948 para cá cerca de 295 acordos internacionais foram negociados e celebrados. ${ }^{44}$

Como se depreende, a opção pela cooperação, em detrimento de conflitos, tem sido cada vez maior nos dias que correm, porque, simplesmente, todos os Estados ribeirinhos tem interesses em salvaguardar, que são interesses comuns, cuja satisfação não se encontra recorrendo a guerras. Por isso, os Estados tendem a recorrer a soluções mais pacíficas para a resolução dos seus diferendos decorrentes do uso e gestão de recursos hídricos internacionais, de forma a ultrapassar as tensões e ambientes políticos desfavoráveis.

Uma análise feita a um total de 1,831 eventos em bacias hidrográficas partilhadas potencialmente conflituosas mostra que os Estados preferem sempre cooperar e evitar $\operatorname{conflitos}^{45}$, tendo vários autores chegado à mesma

\footnotetext{
${ }^{42}$ WOLF, Aaron T. Conflict And Cooperation. Survey of the Past and Reflection for the Future. Water for Peace: A Cultural Strategy. UNESCO-IHP, 2003. p. 93.

${ }^{43}$ WOLF, Aaron T.; YOFFE, Shira B.; GIORDANO, Mark. International Waters: Indicators For Identifying Basins At Risk. UNESCO-IHP, n. 20, 2003. p. 8.

${ }^{44}$ UN-WATER. Transboundary waters: Sharing Benefits, Sharing Responsibilities. UN-Water, 2008. p. 2.
}

conclusão, o que nos leva a concluir que, sem sombra de dúvidas, influencia um efeito cascata de comportamentos positivos nas relações entre Estados que partilham bacias hidrográficas, com tendência à cooperação, ofuscando a retórica de possíveis guerras pela água e polarizando discussões sobre assuntos mais prementes e relevantes. $^{46}$

Este comportamento dos Estados justificase porque em termos sociais, as guerras são muitas vezes causadas por coisas menos importantes que a água, mas que devido à hegemonia, à autonomia, à independência, ou ainda a factores ligados à segurança nacional, oportunidade económica, à justiça ou ainda à sustentabilidade ambiental, os países acabam entrando em conflitos, dependendo o grau de cooperação na capacidade dos Estados em acomodar os interesses em conflito. Na verdade, num ambiente cooperativo, os Estados vão incentivando uns aos outros, mudando de atitude em retribuição da boa vontade um do outro.

Outrossim, isto não significa de modo algum que se deve menosprezar a água como elemento catalisador de conflitos que se podem transformar em verdadeiras guerras, pois a complacência não é, definitivamente o antídoto ao pessimismo de quem defende a iminência de guerras causadas pela água, mas o que queremos sublinhar é que a História, os números e os factos provam que a cooperação sobressai aos possíveis conflitos, e que esta realidade deve ser transformada numa cultura dos países que partilham bacias hidrográficas, pois só dessa forma todos sairão a ganhar.

Mais ainda, se por um lado reconhece-se a existência de numerosos conflitos causados pelo

45 GIORDIANO, Mark A.; WOLF, Aaron T. Sharing waters: Post-Rio international water management. Natural Resources Forum, v. 27, 2003. p. 166.

46 Vide UNITED NATION DEVELOPMENT PROGRAMME. Human Development Report. Beyond scarcity: Power, poverty and the global water crisis. 2006. p. 204. 
uso e gestão de recursos hídricos transfronteiriços, não há nenhum caso conhecido de guerra de grande escala cuja motivação primária tenha sido a água ${ }^{47}$, se bem que os conflito já verificados foram já motivo de muita retórica, alguma até bastante agressiva. ${ }^{48}$

De forma a facilitar o acompanhamento e a ajudar a resolver os conflitos relacionados com a água nas bacias hidrográficas internacionais, foi criada uma base de dados sobre disputas envolvendo recursos hídricos transfronteiriços, num projecto desenvolvido pela Oregon State University Department of Geosciences, em colaboração com a Northwest Alliance for Computational Science and Engineering.

A base de dados inclui um mapa digital das 261 bacias hidrográficas internacionais actualmente existentes, uma compilação pesquisável dos mais de 300 tratados existentes relacionados com bacias hidrográficas internacionais, uma bibliografia anotada com mais de 1000 números sobre o estado geral da resolução de conflitos, e documentos relacionados com a resolução de disputas ligadas à água durante o período de 1950 a 2000, incluindo a descrição de métodos indígenas e ou tradicionais de resolução de disputas. ${ }^{49}$

Há quem faça uma abordagem diferente da questão $^{50}$, olhando para os conflitos pela água como consequência de factores exógenos mas relacionados com a água, que afectam os conflitos e a capacidade de resolução dos mesmos, sendo eles a questão do género ${ }^{51}$, a etnicidade e o desenvolvimento económico desigual.

\footnotetext{
47 Vide UNITED NATION DEVELOPMENT PROGRAMME. Human Development Report Office Occasional Paper: Managing Trans-boundary Waters for Human Development. 2006. p. 7.

${ }^{48}$ Ibid, p. 12 ..

${ }^{49}$ WOLF, Aaron T. Conflict And Cooperation. Survey of the Past and Reflection for the Future. Water for Peace: A Cultural Strategy. UNESCO-IHP, 2003. p. 94.

${ }^{50}$ TROTTIER, Julie. Water Wars: The Rise of a Hegemonic Concept. Exploring the making of the water war and water
}

Entretanto, é necessário distinguir e clarificar conceitos, e mostrar que, por exemplo, se justificações para a inexistência de verdadeiras guerras pela água, quais sejam o facto de as forças do mercado mostrarem que por via da água virtual reduzem-se as necessidades de água para produção agrícola, e com isto verificar-se uma redução pela demanda pela água e consequentemente o nível de conflitos; a tendência de seguir métodos pacíficos de solução de conflitos, mesmo nos casos de tensão existente entre os Estados, causados pela escassez de água ou pela pobre qualidade da mesma.

É preciso todavia perceber que a ausência de guerras pela água não é sinónimo de ausência de conflitos pela água, e muito menos é legítimo pensar que as guerras pela água não são uma realidade. Este seria um erro, pois o espectro da Guerra causada pela água é uma realidade inerente aos recursos hídricos internacionais. ${ }^{52}$

Há várias questões que se podem levantar em relação aos diversos pontos de vista aqui levantados. Por exemplo, não há uma clareza de definições e conceitos, sendo usados termos como conflito, disputa, tensão e Guerra, que são usados como se de conceitos equivalentes se tratasse, que procurámos distinguir e esclarecer.

$\mathrm{O}$ mesmo acontece em relação à indicação clara do papel da água num determinado conflito, havendo quem a apode de meio de conflito, de arma de conflito ou ainda de objecto de conflito, e esta proliferação de termos muitas vezes usados sem a devida precisão não facilita o estudo do assunto.

peace belief within the Israeli-Palestinian Conflict. Water for Peace: A Cultural Strategy. UNESCO-IHP, 2003. p. 55. ${ }^{51}$ A relação que as comunidades estabelecem com a água é em grande medida uma relação de género. Principalmente em África, onde a procura de água, os cuidados da casa e a irrigação das hortas são em princípio tarefas femininas.

52 ZEITOUN, Mark; WARNER, Jeroen. Hydro-hegemony - a framework for analysis of trans-boundary water conflicts. Water Policy, v. 8, 2006. p. 437. 
De igual modo, procurámos fazer uma análise objectiva dos casos de cooperação existentes, mas os mesmos não nos permitem afirmar, com propriedade, a prevalência ou não quer de conflitos ou ainda dos mecanismos de cooperação. Porque não se podem generalizar as situações.

Por outro lado, a variabilidade espacial da ocorrência de conflitos também é um elemento cuja análise deve seguir critérios uniformes. Isto é, conceitos como o de 'stress hídrico' são geralmente usados para referir a situação concreta de um país (tendo em conta, eventualmente, a população em relação às necessidades de água), enquanto os conflitos sobre recursos hídricos transfronteiriços levam em conta a bacia hidrográfica como um todo, sendo natural que, com base nestes dois critérios, por exemplo (portanto stress hídrico vs bacia hidrográfica) a situação pode não ser generalizada, podendo ser diferente de país para país ou de zona para zona, da bacia hidrográfica.

Pelo que é preciso levar em conta nas análises sobre a possibilidade de ocorrência de conflitos, a variabilidade dos diversos parâmetros espaciais como a população, o clima, a disponibilidade de água e os grupos nacionais existentes. Outra questão relacionada a esta tem a ver com o facto de haver uma tendência de a doutrina que trata dos conflitos pela água analisar casos ligados às bacias hidrográficas mais problemáticas, como as do Jordão, TigrisEuphrates, Indus, e Nilo, que levam a conclusões gerais sobre as bacias hidrográficas a nível internacional como sendo tensas, quando na verdade trata-se de situações localizadas que providenciam conclusões incompletas ou parciais e por isso questionáveis.

\section{CONCLUSÃO}

Os recursos hídricos internacionais congregam peculiaridades que os tornam vulneráveis à ocorrência de conflitos. De entre tais características apontam-se pelo menos três. Primeiro, uma tendência de os Estados maximizarem a exploração dos recursos hídricos internacionais, comprometendo o acesso equitativo aos demais Estados ribeirinhos. Em segundo lugar, o egoísmo dos Estados ribeirinhos, que muitas vezes exploram mais do que na verdade necessitam, pelo simples facto de o recurso ser partilhado e haver concorrência. Em terceiro lugar, porque não é fácil alcançar acordos de partilha de cursos de água, pela natureza dos interesses envolvidos, pelo tipo de relações entre os Estados envolvidos, que podem ser boas ou más, sendo por isso a partilha de cursos de água um verdadeiro desafio para os Estados, que pode suscitar conflitos, caso não haja uma acção colectiva que permita alcançar consensos na gestão dos recursos hídricos internacionais.

Os cursos de água internacionais interligam interesses dos Estados ribeirinhos num sistema complexo de interdependência, que cobre diversas esferas como a económica, a das políticas ambientais e a segurança. Todavia, os Estados ribeirinhos gozam de “ independência hidrológica", sendo-lhes reconhecido o direito soberano de explorar recursos hídricos de que são ribeirinhos. E há três áreas de preocupações, ou de interesse, que podem ser levantadas entre os países que partilham águas e que são invocados como justificação da “ independência hidrológica": os interesses relacionados com a soberania; os interesses relacionados com a integridade territorial; e os interesses relacionados com a segurança nacional.

As relações entre os Estados ribeirinhos tornam-se mais frágeis devido à crescente escassez de água que assola muitos países. Este facto pode levar à perda de independência hidrológica, agravando a interdependência hidrológica, e em bacias hidrográficas com escassez de água este facto pode criar um potencial para conflitos entre os Estados de bacia. 
A existência de assimetrias de poder entre os Estados ribeirinhos (em termos de poder económico, capacidade militar, tamanho do Estado, etc.) pode interferir na obtenção de um acordo justo e sustentável entre os Estados que partilham águas, e esta é uma potencial causa de conflitos.

As políticas em relação às quais determinada bacia hidrográfica se subordina, providencia os parâmetros dentro dos quais a gestão dos recursos hídricos transfronteiriços deve ser analisada. Porque existe um potencial poder unificador que um curso de água internacional providencia, é necessário aprofundar o diálogo. A celebração de acordos de bacia tem sido, a nível político, a solução prática para evitar e ou resolver conflitos sobre águas transfronteiriças. Muitas vezes, as águas partilhadas são vistas, por isso, como factor de aproximação e não de conflito, entre os Estados ribeirinhos.

De facto, a água é muitas vezes um elemento mitigador de conflitos e consequentemente de guerras por ser um elemento que induz à cooperação mesmo aos
Estados ribeirinhos hostis, mesmo em disputas que tenham objecto diferente da água. Este factor faz com que as disputas causadas pela escassez de água não sejam muitas, e as poucas existentes não se transformem em verdadeiras guerras, apesar de reconhecermos que a escassez de água em quantidade e qualidade é um dos maiores factores de desestabilização nas regiões que partilham bacias hidrográficas.

A ausência de guerras pela água não é sinónimo de ausência de conflitos pela água, e é incorrecto pensar que as guerras pela água não são uma realidade, pois o espectro da Guerra causada pela água é uma realidade inerente aos recursos hídricos internacionais. Todavia, não há uma clareza de definições e conceitos, sendo usados termos como conflito, disputa, tensão e Guerra, que são erradamente usados como se de conceitos equivalentes se tratasse. De igual modo, é necessário distinguir os vários papéis da água num determinado conflito, porquanto ela pode ser meio de conflito, arma de conflito ou ainda de objecto de conflito, e esta proliferação de termos, muitas vezes usados sem a devida precisão pode dificultar a busca de soluções.

\section{REFERÊNCIAS}

ALLAN, J. A. Nile Basin Water Management Strategies. In: HOWELL, P. P.; ALLAN, J. J. (Ed.). The Nile: Sharing a Scarce Natural Resource: A Historical and Technical Review of Water Management and of Economic and Legal Issues, 1996.

AMERY, Hussein A. Water, War and Peace in the Middle East: Comments on Peter Beaumont. The Arab World Geographer, v. 4, n. 1, 2008.

ANNAN, Kofi. Question and answer session after statement at the Federation of Indian Chambers of Commerce and Industry. SG/SM/7742, New Delhi, 15 mar. 2001.

BENVENISTI, Eyal. Collective Action in the Utilization of Shared Freshwater: The Challenges of International Water Resources Law. AJIL, v. 90, n. 3, 1996.

BENVENISTI, Eyal; GVIRTZMAN, H. Harnessing International Law to Determine IsraeliPalestinian Water Rights: The Mountain Aquifers. Natural Resources Journal, v. 33, n. 3, 1993. 
ELMUSA, Sharif S. Dividing the Common Palestinian-Israeli Waters: An International Water Law Approach. Journal of Palestine Studies, v. 22, n. 3, 1993.

GIORDANO, Mark F.; GIORDIANO, Meredith A; WOLF, Aaron T. International Resource Conflict and Mitigation. Journal of Peace Research, v. 42, n. 1, 2005.

GIORDIANO, Mark A.; WOLF, Aaron T. Sharing waters: Post-Rio international water management. Natural Resources Forum, v. 27, 2003.

GLEICK, Peter H. The World's Water: The Biennial Report on Freshwater Resources 1998-1999. Washington, D.C.: Island Press.

GLEICK, Peter H. Water and Conflict: Fresh Water Resources and International Security. International Security, v. 18, n. 1, 2003.

HEYNS, Piet S. SADC agreements in existence pertaining to shared water resources. In: Water and Security in Southern Africa, SIDA, Stockholm, 1995.

HEYNS, Piet S. Water resources management in Southern Africa. In: International Waters in Southern Africa. Tóquio: United Nations University Press, 2003

LIBISZEESKI, Stephan. Water Disputes in the Jordan Basin Region and their Role in the Resolution of the Arab-Israeli Conflict. Occasional Paper No. 13. Center for Security Studies and Conflict Research, Zurique, 1995.

MOHAMED-KATERERE, Jennifer; VAN DER ZAAG, Pieter. Untying The 'Knot of Silence'. Making Water Policy and Law Responsive to Local Normative Systems. Water for Peace: A Cultural Strategy. UNESCO-IHP, 2003.

MOSTERT, Erik. Conflict and Cooperation in the Management of International Freshwater Resources: A Global Review. UNESCO-IHP, n. 19, 2003.

PHILIPS, David J. H.; DAOUDY, Marwa; MACCAFFREY, S.; ÖJENDAL, Joakim; TURTON, Anthony. Trans-boundary Water Cooperation as a Tool for Conflict Prevention and for Broader Benefit-sharing. Ministry for Foreign Affairs, Stockholm, Suécia, 2006.

REUSS, Martin. Historical Explanation and Water Issues. Water for Peace: A Cultural Strategy. UNESCO-IHP, 2003.

TROTTIER, Julie. Water Wars: The Rise of a Hegemonic Concept. Exploring the making of the water war and water peace belief within the Israeli-Palestinian Conflict. Water for Peace: A Cultural Strategy. UNESCO-IHP, 2003.

TURTON, Anthony R. Hydro hegemony in the context of the Orange River basin. Paper presented at the Workshop on Hydro Hegemony, Kings College and the School of Oriental and African Studies (SOAS), Londres, 20-21 mai. 2005.

TURTON, Anthony R. The evolution of water management institutions in selected Southern African international river basins. In: TORJADA, C.; UNVER, O.; BISWAS, A. K. (Ed.). Water as a Focus for Regional Development. Londres: Oxford University Press, 2004. 
TURTON, Anthony R. The hydropolitical dynamics of cooperation in Southern Africa: A strategic perspective on institutional development in international river basins. In: ; ASHTON, P.; CLOETE, T. E. (Ed.). Transboundary Rivers, Sovereignty and Development: Hydropolitical Drivers in the Okavango River Basin. Pretoria e Genebra: African Water Issues Research Unit e Green Cross International, 2003.

TURTON, Anthony R. The Political Aspects of Institutional Development in the Water Sector: South Africa and its International River Basins. 2003. Tese (Doutorado em Ciência Política)-University of Pretoria, Department of Political Science, 2003.

UNITED NATION DEVELOPMENT PROGRAMME. Human Development Report Office Occasional Paper: Managing Trans-boundary Waters for Human Development. 2006.

UNITED NATION DEVELOPMENT PROGRAMME. Human Development Report. Beyond scarcity: Power, poverty and the global water crisis. 2006.

UNITED NATIONS. Transboundary Waters. Water for life decade. Disponível em: <http://www.un.org/waterforlifedecade/transboundary_waters.shtml>. Acesso em: 26 out. 2016.

UN-WATER. Transboundary waters: Sharing Benefits, Sharing Responsibilities. UN-Water, 2008.

WOLF, Aaron T. Conflict and Cooperation Along International Waterways. Water Policy, v. 1, n. 2, 1998.

WOLF, Aaron T. Conflict And Cooperation. Survey of the Past and Reflection for the Future. Water for Peace: A Cultural Strategy. UNESCO-IHP, 2003.

WOLF, Aaron T.; YOFFE, Shira B.; GIORDANO, Mark. International Waters: Indicators For Identifying Basins At Risk. UNESCO-IHP, n. 20, 2003.

ZEITOUN, Mark; WARNER, Jeroen. Hydro-hegemony - a framework for analysis of trans-boundary water conflicts. Water Policy, v. 8, 2006.

ZEITOUN, Mark; MIRUMACHI, Naho. Transboundary water interaction I: reconsidering conflict and cooperation. International Environmental Agreements, Springer, 2008.

Recebido em: 15/05/2017

Aceito em: 10/08/2017 
